\title{
Conceptions and Representations of the Sentencing Decision Process
}

\author{
Cyrus TATA*
}

\section{INTRODUCTION}

This article attempts to reflect on the success of attempts by academic research to understand and explain the sentencing decision process. It identifies conventional themes in the conception and representation of that decision process and argues that there are some important difficulties associated with them and consequently implications for both the findings of sentencing research and for approaches to sentencing reform. The article suggests a possible alternative approach to conceptualizing and representing the sentencing decision process and also raises questions about the nature of the discretionary (legal) decision process more generally.

I will argue that a predominant tradition in sentencing research is based on a 'legal-analytical' paradigm which posits legal categories as the starting point for interpreting sentencing and then attempts to 'add in' supposedly discrete pieces of information about a case as if they were independent 'factors'. An alternative approach, offered by this article, begins from the recognition that the criminal process constructs and reconstructs cases for the purpose of sentencing as 'typical whole case stories'. Although the implications for sentencing reform, (for example, 'Guidelines') and the role of philosophical justifications of punishment will be discussed, it is not the primary aim of this article to suggest either how sentencing ought to be reformed (or not); nor, to describe how sentencing research should operationalize an approach based on 'typical whole case stories'. Rather, my purpose here is

\section{* Research Fellow, Law School, University of Strathclyde, Stenhouse} Building, 173 Cathedral Street, Glasgow G4 ORQ, Scotland

An earlier version of this article was presented at the Joint Meetings of the Law and Society Association and the Research Committee on the Sociology of Law of the International Sociological Association, 10-13 July 1996. It has since benefited from comments at that meeting and also from improvements suggested by Simon Halliday, Neil Hutton, and Denise Mina. I am grateful to them for their generous assistance. I would also like to thank the anonymous reviewers of this article for their helpful comments. 
to suggest that there may be a gap between how sentencing decisions are processed in practice and the conceptual starting points which research has employed to interpret that practice.

Internationally, over the last twenty-five years there has been a very substantial body of attempts to try to reform sentencing practise. However, in practice the successful implementation of reform has been notoriously difficult to achieve. If we are to try to make sense of this experience then perhaps we should re-examine some of the predominant assumptions about the sentencing decision process.

\section{THE SEARCH FOR 'EXPLANATIONS'}

Sentencing is frequently seen as one of the clearest examples of an area where decision-makers enjoy very wide discretion. ${ }^{1}$ Yet, despite the interest which it has received from both academic and journalistic investigators, a number of commentators have noted that we actually possess fairly little understanding of the nature of the sentencing decision process. For example, Lacey observes that:

[t]raditionally criminal lawyers have shown little interest in this highly discretionary area, but over the last fifteen years, reporting of sentencing cases and renewed academic interest in Britain (to take an example) has revealed the extent of judicial and magisterial discretion and of disparity in its exercise among different judges and magistrates ... [T] he main focus of the debate has been on disparity ... concerning what happens rather than why this is the case ... .

Similarly, Rumgay notes that, "the explanation for discrepancies within individual courts in their treatment of like cases remains elusive. ${ }^{3}$

However, both of these statements seem to imply that it is possible to divorce a straightforward description of sentencing (what Lacey calls 'what happens') from its explanation ('why this is the case'). Rather, I would suggest that questions of 'description' and 'explanation' are rather more intimately connected. The attempt to describe and measure 'disparity' necessitates some attempt to explain it through some kind of image of 'similarity' between the object of the decision: 'cases'.

I shall suggest that our ability to understand and 'explain' (and therefore to 'describe') the sentencing process has been limited by a particular set of assumptions about 'similarity' between cases which have produced a limited conception and representation of the sentencing decision process. I shall suggest an alternative way of conceptualizing and representing the sentencing process. ${ }^{4}$

\section{SENTENCING AS A COMPARATIVE PROCESS}

I would like to begin by emphasizing that the act of sentencing is fundamentally a comparative process. 
It is, of course, an axiom of judicial rhetoric on sentencing that every case is unique and as such each case must be judged on its own facts. ${ }^{5}$ Further, it is argued that because each case is unique it is therefore not possible to compare one case with another. However, the untenability of this claim was exposed by Hood writing nearly twenty-five years ago:

... magistrates and judges frequently turn to precedent for their ruling and place particular value on their experience in sentencing. Now, if this experience is to be of value, then all cases cannot be unique, they must be comparable at least in some respects; and even if it is agreed that all cases are unique in some sense, this cannot be decisive in the practice of sentencing, for frequently decisions are reached with the aid of 'experience'. ${ }^{6}$

Similarly, Wilkins observes that:

[n]o unique or once and for all event can be any guide ... We can only use information as a guide when we are prepared to consider similarities, not when we are emphasizing differences (uniqueness) to the exclusion of all other considerations. ${ }^{\text {? }}$

To recognize 'difference' we must also recognize 'similarity': the two are different sides of the same coin. Since necessarily it must be possible, at least in principle, to compare cases and thus to investigate judicial conceptions of 'similarity', how can and should this 'similarity' be understood?

\section{THE ABILITY TO UNDERSTAND AND REPRESENT 'SIMILARITY'}

Official statistics ${ }^{8}$ and a number of academic studies have attempted to employ the notion of 'case similarity" by comparing the sentencing decisions of courts according to the same criminal law convictions (for example, 'theft', 'robbery', 'assault', or convictions under a particular section of an Act of Parliament) or aggregations which are based on official criminal law convictions. According to this approach, it is then possible to compare meaningfully the sentences passed according to the same official, legal headline convictions. It might then safely be concluded that any variation in sentencing found is not due to any systematic variation in the similarity of the offences for which the offenders had been sentenced. For example, Patchett and Mclean assumed that courts in their sample dealt with similar types of offenders. ${ }^{10}$ Green controlled for intake by prediction methods. " Hood controlled for offence similarity by restricting his study to property offenders aged twenty-one and over. ${ }^{12}$ Tarling compared the sentencing of seventy magistrates' courts by controlling for three variables: type of offence (officially defined), age of the offender, and whether or not s/he had any previous convictions. ${ }^{13}$ Citing earlier research, Tarling argues that although further information about the offence and offender were not available, this 'may not be a serious omission. ${ }^{14}$ Intriguingly, however, Tarling later reports how discussions with justices and clerks showed that ' $\ldots$ in general it was thought that differences in the sorts of crimes dealt with by different courts 
precluded any useful comparisons between their sentencing policies.'15 However, for two reasons, this is not necessarily a safe conclusion to draw.

First, sentencers consider the circumstances of the events surrounding the commission of a legal offence. Previous research, shows that sentencing is determined by far more than the legal definition of the offence(s). ${ }^{16}$ The 'headline' offence(s) (for example, 'robbery', 'rape', 'theft', and so on) with which an offender is charged and convicted may be of limited relevance in deciding sentence.

Reliance on the official 'headline' conviction may be unsafe for a second reason. Even though in their samples, researchers may attempt to control case similarity in terms of the headline conviction, the nature (and seriousness) of cases coming before different sentencers may vary systematically. It is quite possible, even likely, that different courts, or even different sentencers in the same court, will be required to sentence caseloads whose seriousness varies systematically. Even though different headline convictions may be the same, it is likely that this legal similarity may mask an underlying and systematic variation in seriousness. So the caseload of different courts 'robberies' or 'thefts' or 'assaults' or 'section 112s' may vary markedly in seriousness. Differing approaches to prosecution may vary between prosecution offices, possible variation in judicial practices in the deferment of sentence ${ }^{17}$ and the administration of the courts and the process of information flows ${ }^{18}$ may all act singly or in combination to present different sentencers with systematically distinct caseloads in terms of their relative seriousness.

\section{The conception and representation of similarity needs to be organized} from the perspective of sentencing

As we saw above, research investigating sentencing disparity has often portrayed the sentencing process as simply using official legal taxonomy as its sole or main starting point. On the basis of more recent research with judges, ${ }^{19}$ I would suggest that we need to think more imaginatively about our representations of similarity from the perspective of sentencing. This may mean that the representation of similarity will not necessarily reflect the content and structure of the criminal law. We need to represent sentencers' interpretation of similarity from the perspective of sentencing rather than from the perspective of a taxonomy of legal convictions which would involve a slavish repetition of official criminal law classifications. ${ }^{20}$ This may mean a fuller 'description' and 'explanation' of sentencing.

\section{Similarity of cases sentenced where there is more than one conviction}

In trying to represent sentencers' understandings of similarity, one question seems to have been neglected. ${ }^{21}$ How can the similarity and seriousness of cases be captured where sentences are passed for cases where there is more than one conviction? 
It appears to be common practice in jurisdictions around the world to prosecute a person in court for more than one charge at one time. The problem lies in the fact that one "case'22 may be sentenced for a number of convictions. How should this case be recorded and represented by researchers? There appear to be a number of possible options.

\section{(a) A 'multi-sentence' approach?}

It might be supposed that each individual conviction within a case should be recorded against each individual corresponding sentence within a case. However, such a multi-sentence approach depends upon two presumptions. The first presumption is that all convictions within a case are sentenced separately by judges. While this does happen, many sentences passed in Scotland (for example) are separate convictions which are passed in conjunction with each other: 'in cumulo', 'concurrently' or indeed 'consecutively', or, any combination of these. The second presumption would be that sentences passed separately ('consecutively') do not influence each other in practice. Even in those cases where sentences are formally passed separately, it is almost inevitable that, in practice, the consecutive sentences do in fact influence each other. Sentencers tend to view one offender convicted of more than one conviction on one 'indictment' or 'complaint' as a whole case rather than as merely separate legal convictions abstracted from each other. ${ }^{23}$

How, then, should sentences for cases with more than one conviction be recorded? What is needed is a way of recording information about sentences for offences which more closely reflects the way in which judges think about sentencing.

\section{(b) A 'principal sentence' approach}

An approach to recording and representing information about sentencing practice based on 'the principal sentence' can be found in representations provided by the recording schemes of official statistics. These record the sentence against a principal 'headline' conviction (regardless of the circumstances of the commission of the offence). The main conviction, however, is defined by the conviction which is judged to have received the most 'punitive' sentence. Often, the 'headline' conviction which receives the most severe sentence will be regarded by sentencers as the most serious conviction. ${ }^{24}$ However, the seriousness of a headline conviction is by no means the only determinant of sentence. Rather, to regard the conviction which receives the most punitive sentence as necessarily the most serious conviction is to offer only an indirect account of the principal (or most serious) conviction. In addition to the circumstances of the commission offence, other circumstances, such as the previous record of the offender, (not to mention the awareness of parole eligibility), can be important determinants of a more or less severe sentence for one offence than another even if the offence with the lesser sentence is otherwise more serious. Therefore, in view of its ability 
to provide at best only a probable indication of the principal offence, this approach would be better described and recognized as a 'principal sentence' approach rather than a 'principal offence' approach. It does not directly record or represent the most serious offence, but rather the most severe penalty which may or may not coincide.

\section{(c) A 'principal offence' approach?}

What is described here as the 'principal offence' approach has tended to be the most common way that sentencing researchers have recorded the sentence passed for cases where there is more than one conviction. ${ }^{25}$ This approach may be based on strict legal conviction taxonomy, ${ }^{26}$ or attempt to develop some more generic representations of offence incidents. ${ }^{27}$ However, the rationale for this approach is that judges often feel that one conviction is clearly the more or most serious in a case. For example, it may be felt by sentencers that some charges are libelled on an indictment for evidential reasons and as such held weight for the purposes of securing conviction on a main charge rather than for the purpose of considering sentence. It is often felt that there is often one principal offence for which sentence was really passed. Additional convictions may be considered to be incidental or of much lesser seriousness. They are often regarded as essentially 'factors' which may modify the relative seriousness of the principal conviction. ${ }^{28}$

Although the principal offence approach has been employed in various contexts, I would argue that it is subject to important limitations.

Consider a typical kind of case before the Scottish High Court. A man is convicted of three charges libelled on an indictment. Two of these convictions are for sodomy against two boys and one is for rape against a girl. Which is the principal offence? It is not immediately apparent. The principal offence approach requires that one offence is selected and recorded by the researcher as the most serious and further factors may be included as characteristics of that principal offence, such as number of victims of the principal offence; number of offences of the principal offence, and so on. This approach to recording and representing information about sentencing means that the output of such research artificially privileges one conviction over another.

Rather than regarding it as merely two convictions of sodomy and one of rape, judges considering sentence tend to view the case as a whole: a case of a father sexually abusing his children systematically over a long course of time; a case of 'aggravated child abuse'. This may be seen by the judge as similar to other sexual abuse cases aggravated by the course of conduct and/or nature of the offences. In the attempt to represent similarity, the principal conviction approach can miss potentially similar cases. Therefore, some broad distinctions need to be made between relatively 'ordinary' child sexual abuse and the more serious, aggravated type of case.

Let us take another example: eight convictions of 'theft' of items of a similarly low value from eight different shops during one day. Using a principal 
offence approach, one of the thefts would have to be privileged as 'the main offence'. To do so would fail to capture the relative seriousness of the offenceincident compared with cases where, in similar circumstances, there was only one of two convictions. Sentencers have reported seeing the former as a kind of 'professional shop-lifting' as opposed to a more amateurish variety. ${ }^{29}$

\section{An approach based on 'typical whole offence stories'}

I would suggest that one way to resolve the intractable problem of representing similarity in multi-conviction cases is to try to develop a series of different types of offence stories which would reflect the way in which sentencers think about offence information as a whole.

In considering sentence, judges do not think about each conviction in a multi-charge indictment in isolation from each other and from the circumstances of the commission of the offences. Rather, they tend to view the case as a whole offending incident or narrative of criminal events, or 'typical whole offence stories'. ${ }^{30}$ In attempting to understand (both 'describe' and 'explain') the process of the decision-making of sentencers, empirical research with judges has used sentencing vignettes rather than necessarily relying on criminal law classifications which are necessarily limited in the relevant information which they can offer the sentencer. ${ }^{31} \mathrm{~A}$ very limited attempt to realize this approach has been adopted by a project to design and implement a sentencing information system for the Scottish High Court. ${ }^{32}$ Therefore, it is necessary to depart from the classifications of the criminal law in order to reflect more closely the way that judges think about sentencing different types of offence stories.

\section{(a) A typology of offence stories from the perspective of sentencing}

Types of whole offence stories may be broadly distinguished in terms of their relative seriousness. A simple example relates to several driving convictions under the Road Traffic (Scotland) Act 1988. Typically, an offender may be convicted of three offences under this Act involving 'taking a vehicle without the owner's consent' (s. 143), driving without insurance (s. 178), driving without due care and attention (s. 2). Rather than having to choose a notional principal offence, sentencers conceive of this as part of a typical whole offence narrative or story which might be reflected by the term 'joyriding'. Similarly, terms such as 'aggravated child abuse' and 'professional shop-lifting', as discussed above, have been employed. I would suggest that sentencers approach the sentencing decision by thinking of an offenceincident, or series of related incidents (what lawyers might call a 'course of conduct') as 'typical whole offence stories'. Yet, does an approach based on typical whole offence stories over-simplify and stereotype what is often said to be a highly complex decision process? 
(b) Is an approach based on typical whole offence stories too crude?

It may be objected that the attempt to produce a 'holistic typology' of offences ${ }^{33}$ for sentencing research is overly simple since the very idea of 'types' of cases denies the delicate and subtle complexities of the 'knowledge' represented by the criminal law. However, to make such an argument is to lose sight of the fact that this 'knowledge' is created for a particular purpose: securing convictions and acquittals. ${ }^{34}$ All legal convictions are themselves typologies. Indeed, research in other areas of the criminal process has shown the ways in which formal 'discretion' becomes patterned, and standardized and cases become 'typical'.

Shapland has noted the relative isolation of the sentencing decision and reliance on largely documentary sources. ${ }^{35}$ In common with prosecutors and parole board members, there are, she notes, '. . f few others in the criminal justice system who are in the position of having to take decisions largely on the basis of documentary sources - the "file". ${ }^{36} \mathrm{Far}$ from popular images informed by lengthy, high-profile cases, the overwhelming mass of sentencing in the English-speaking world is conducted in the absence of a trial. ${ }^{37}$ Sentencers have to take decisions almost entirely on the basis of the file which has been constructed, restructured, and altered (sometimes radically) at every point in the criminal process before sentencing.

This is perhaps similar to the situation in which prosecutors find themselves at an earlier stage in the criminal process. Baldwin's study of 'pretrial settlement' in magistrates' courts observes the importance of 'pre-trial review' ${ }^{38}$ From his participant observation research of police detective work, Waegel concludes that, '[a] great deal of actual detective work may . . . be seen as a process of mapping the features of a particular case onto a more general and commonly recognized type of case. ${ }^{39}$ Moody and Tombs have shown that prosecutorial decision-making is largely determined by the previous structure given to the case by the police, by notions of 'normal' crimes', ${ }^{40}$ and by long established working practices. ${ }^{41}$ For example, in police reports, (which the Procurator Fiscal's offices use to draft charges), generally:

the report focuses on the offence itself and the ingredients deemed necessary for proving the offence. The language is stereotyped and the thrust of the presentation is towards minimising uncertainty . . .42

The charges themselves are drafted in a finite variety of ways which have the effect of standardizing and normalizing reports of relatively complex human behaviour:

[I]t is remembered that charges may be drafted in a standard way commonly referred to by fiscals as a style ... [and it is a] ... process of assimilating prosecutorial norms and rendering the unfamiliar familiar ....43

In his study of the Scottish public prosecutor's decision to divert persons away from prosecution to psychiatric care, Duff also emphasizes the way in which the prosecutor's formal discretion is largely determined by the previ- 
ous structure given to the case. He argues that the prosecutor's decision is in practice largely determined by the routine cues and signals provided by the police report to the prosecutor's office. ${ }^{44}$ Sudnow reports research examining the operation of the Public Defender system in the United States of America. In the course of routinely encountering persons charged with offences, the Public Defender (P.D.) learns to identify what Sudnow terms 'normal crimes'. ${ }^{45}$ These are:

... those occurrences whose typical features, e.g., the way they usually occur and the characteristics of persons who commit them (as well as the typical victims and typical scenes), are known and attended to by the P.D. ${ }^{46}$

Indeed, Sudnow observes the importance of this practical, working knowledge:

Knowledge of the properties of offense types of offenders, i.e., their normal, typical, or familiar attributes, constitutes the mark of any given attorney's competence. A major task in socializing the new P.D. deputy attorney consists in teaching him to recognize these attributes and to come to do so naturally. ${ }^{47}$

This process of familiarizing and normalizing cases continues when reports about the social and personal circumstances are made to the court. In an analysis of social enquiry reports in Scotland, Curran and Chambers note the constructed nature of the reports describing them as 'persuasive documents' 48 and Brown argues that the social enquiry report ' ... presents a set of representations about the defendant which seeks to promote a particular picture of that defendant for a particular purpose. ${ }^{39}$ Giller and Morris found that social workers use 'operational philosophies' (the means by which professional ideologies are mediated through the demands of practice): $:^{50}$

Having located the moral character of the case, the social workers were able to respond with a repertoire of provisions which routinely met the case as portrayed. In this way, social work with offenders became ordered and rational and a work priority was established. Decisions were not 'made'; they emerged as natural logical, even inevitable, responses to the social worker's interpretation of the case. But these interpretations were part of a dialectic. What 'explained' the moral character of the case also provided evidence of its nature."

This finding is confirmed by other research into problem-solving by other professionals, such as doctors who have to make diagnoses. Elstein et al. found that the doctors appeared to do a simpler job than they imagined, making use of simple conceptual schemata. ${ }^{52}$ While individual cases may be repeatedly normalized and typified, Emerson emphasizes that assessments about the seriousness of individual cases are not made in isolation from each other but, rather, within the organizational context of 'streams of cases' and that this, rather than the individual case, should be seen as the basic category for understanding 'social control decision making'. ${ }^{53}$

So, it is not that actual human behaviour (including that labelled 'criminal') which is necessarily typical or patterned, but that the accounts or 'stories' of it presented to and interpreted by sentencers are patterned, normalized, and typified. Access to the social world is not direct or unmediated: the criminal process necessarily must impose some narrative or interpretatative order upon it. 
Much of the research discussed above draws on work into the use of discretion in the criminal process to try to illuminate the character of the discretionary decision process in sentencing. It may be argued, however, that the status of the sentencer is qualitatively different from others in the criminal process since $s /$ he is the only one who has all the facts about the case.

(i) The position of the sentencer in 'being in possession of all the facts'

Although decision-makers in other parts of the criminal process develop informal patterns of representation of information, and behaviour, does the sentencing process function in a way distinct from that of other criminal decision processes? Does the attempt to produce "typical whole offence stories' ignore the unique position of the judge in hearing the 'all the facts' of the case? I do not think so. Shapland, ${ }^{54}$ Ashworth et al., ${ }^{55}$ and Feeley ${ }^{56}$ suggest that what lawyers refer to as the 'facts of the case' should not properly be regarded as 'facts' but as:

. . . constructions of the circumstances forming the offence, stemming from the constructions made by the police (themselves very much negotiable and influenced by the individual views of detectives and the wishes of victims and witnesses) (Ericson 1981, Ericson 1982). ${ }^{57}$

Bearing in mind this 'information throughput' model, evidence gathered by the prosecution is refracted through the lens of a series of common law and statutory lenses. It can never be a notionally precise historical account of human behaviour, but must always be a pragmatically constructed representation of it. ${ }^{58}$ Nicholson notes that a minority of sentencers in her research sample disliked the use of the term 'recommendations' in social enquiry reports: ${ }^{59}$

Their argument was that social enquiry report authors were not in possession of all the facts concerning any case were therefore not in a position to recommend sentences to the court. .0

The implication is that only the sentencer is in possession of all of the 'facts'. However, these are only objectively factual in a self-referential sense. The evidence before the sentencer cannot provide an objective factual account of human behaviour merely 'constructed conventions',61 a pragmatic, purposive, and negotiated representation of a notional objective reality. The nature of criminal events and criminals may be infinitely unique but the nature of their legal representations are necessarily finite, typical, and exhaustible. The construction of criminal cases both before and during the judicial sentencing process are accounts which must satisfy particular requirements which may in turn validate these accounts as 'true', or, 'accurate'.

If the character of the decision process in sentencing may not be qualitatively distinct from that of other points in the criminal process because cases are typical constructed accounts rather than full or objective 'facts', then might the sentencing decision process be distinct in another sense? Is the process of the exercise of discretion within an adjudicative setting (sentencing) 
fundamentally different from that within an administrative setting (for example, police, prosecution, social work decisions) as described above?

(ii) Is the sentencing decision process different from the administrative decision process?

I would suggest that the decision process may be not be very different in character, but that there are of course key activities of public justification which are more symbolically important in the adjudicative setting than in an administrative one.

Judges frequently turn to the cumulative and evolved wisdom of judicial experience represented by precedent for their decisions and also place particular emphasis on their personal experience. This 'experience' may help judges in interpreting and schematizing the mass of information which helps to inform their decision. From his field experimental research into the psychology of decision-making of criminal sentencing, van Duyne found that despite the considerable discretion which it afforded, prosecutorial decision-making could be characterized as:

. . . one dimensional: the Prosecutor selected out of the total information on the case only those aspects which were consistent with a particular 'dimension' (e.g. 'professional', 'social misfit' or rehabilitation) and fitted these into simple conceptual schema [sic]. ${ }^{62}$

Although the prosecutor may make a few changes, the decision process remains basically the same. Van Duyne concludes that the results cast some doubt on the claim that:

... sentencing is a highly complex process solely directed to 'unique' decisions in 'unique' cases. Without suggesting that the job of judges is just a matter of quick guesswork and routine, gilded with pomp and ceremony, I would like to state that judicial decision making is comparable to other kinds of open problem solving ${ }^{63}$ such as the grading of works of art by a viewing committee or the marking of an essay by a teacher. If sentencing is difficult, it is because of its uncertainty, not because of its complexity . . In problem solving, [it is] necessary to restrict the information to one manageable dimension in order to avoid overload and uncertainty ... There is no reason to assume that judges and prosecutors are a complex subdivision of the human race deserving a theory of their own.

So I would suggest that in trying to conceptualize and represent offence similarity from the perspective of sentencing, it would be profitable for research to try think about typical whole case stories and rely less on the criminal law to inform our understandings of the sentencing process. One possibility might be to try to develop what has elsewhere been called 'a schematic-holistic approach' 64 which has been developed with judges to design and implement a Scottish sentencing information system. ${ }^{65}$ Essentially this groups offence information about cases together on the basis of a number of typically shared characteristics. As an approach which is specifically designed for the purpose of representing knowledge about sentencing from the exclusive perspective of sentencing, it produces a more sensitive taxonomic tool than that designed by the criminal law. However, such an 
approach could be developed much further. It may be possible to develop typical whole case stories from the perspective of the task of sentencing and thereby avoid the difficulties which I shall argue are associated with the notions of 'aggravating and mitigating factors' and an 'offence/offender' dichotomy. First I shall discuss 'aggravating and mitigating factors' as a category of conception and representation of the sentencing decision process.

\section{4. 'Aggravating and mitigating factors' and the analytical approach}

The notion and language of aggravating and mitigating 'factors' is embedded in reason-giving accounts of decisions by sentencers, popular media and legal analysis. However, the notion may in fact obfuscate the sentencing decision process by presenting it as an artificially analytical process.

Ashworth et al. discuss the interpretative nature of assigning information as having the status of being a 'factor' ${ }^{66}$ Criminal law and sentencing texts list what they have distilled as being 'factors' which aggravate and mitigate sentence. ${ }^{67}$ Research has employed the idea of case information which can be extracted and analysed to discern the relative explanatory power of individual 'pieces' of information. ${ }^{68}$ Conforming with the image of justice weighing each 'factor', there seems to be an assumption that sentencing is derived from a consideration of the legal conviction followed by a duellist process of aggravation and mitigation. ${ }^{69} \mathrm{I}$ would argue that the reality is better represented by the idea of basic types of whole narratives or stories. ${ }^{70}$

There does not seem to be agreement about information which 'aggravates' and which 'mitigates' sentence. Shapland found as many as 229 'mitigating factors'. ${ }^{7}$ Some of these were seen as aggravating in other cases (for example, drunkenness). 'It is even possible for opposite traits to be used in the same case to portray two totally different "deserving" types of people."72 Take the example of the employment position of an offender about to be sentenced. The same information may both aggravate the seriousness of one case and mitigate the seriousness of another. Being able to retain a job might mitigate against a custodial sentence, or, being jobless might evoke greater sympathy for an offender's personal predicament. The same information may be aggravating and mitigating in the same case. Similarly, Tonry observes that '[m]any other regularly recurring circumstances are situationally relevant to sentencing but not universally relevant' ${ }^{73}$ This illustrates the essentially interpretative and case-contextual nature of 'aggravating' and 'mitigating' factors. The meaning of seriousness is fluid and relative to (and only meaningful within) the context of its typical whole offence story.

Judges stress their treatment of cases as a 'whole' and the 'feel' for individual cases. There has been judicial resistance ${ }^{74}$ to the attempt to represent sentencing according to some mathematical model associated with the addition and subtraction of 'independent' 'factors'. ${ }^{75}$ I would suggest that this resistance should not (with the benefit of hindsight) be entirely surprising. 
Such an attempt to model the sentencing decision is to misrepresent decision-making as a deductive, linear, analytical, and mechanical activity. Rather, routine decision-making which is strongly characterized by formal discretion can be better understood as a process of gradual affirmation or denial of a provisional solution to a problem by informally employing typical or typical whole case stories built up through comparative experience.

Weigend notes the inadequacy of 'Aggravating and Mitigating Factors' in explaining sentencing:

The isolation of the aggravating and mitigating factors that influence a court . . . does not enable one accurately to predict sentencing decisions. What is missing is the point of departure: what is the 'normal' sentence for the 'normal' case of larceny, drunken driving, fraud, or assault? . . Mathematical models suggested by some German writers ... have failed to rationalize the sentencing process because it is impossible to draw reliable conclusions from the aggregate of largely irrational and unquantifiable factors. ${ }^{76}$

However, he appears to attribute that failure to the 'unreasonableness' of sentencers rather than the failure of reliance on such a mathematical, analytical model: 'When reason fails tradition steps in. ${ }^{77}$ The implication here seems to be that because sentencing decisions cannot be 'predicted' adequately through the use of an analytical, mathematical model, the explanation for this inadequacy must lie in the replacement of 'reason' by 'tradition' in sentencing. Rather, might one just as easily conclude that the inability to predict sentencing decisions from one perspective (the analytical, mathematical one) should lead us to re-evaluate the adequacy of that analytical approach and contemplate the possibility of alternative approaches?

Yet the revelation that the sentencing decision process does not conform to the deductive, legal-analytical image seems to be a source of a degree of disappointment to some writers. It is considered to be an ideal towards which judges ought to strive. For example, observing that the Victorian Full Court 'reaffirmed the instinctive synthesis' view of sentencing, Fox argues that further 'dissection'78 of cases by judges 'explaining' their sentencing decision process is welcomed as ' . . . being more informative about the manner in which they reach their decisions. Such openness can only benefit the jurisprudence and psychology of judicial sentencing. ${ }^{79}$

The implication here is that the public declaration of reasoning openly explains the decision process and that an intuitive account of sentencing simply does not provide an adequate explanation of the process. ${ }^{80}$ On the contrary, I would suggest that an intuitive account may in fact provide us with a more transparent understanding of the kind of process of sentencing based on 'typical whole case stories' which become so routinized that they become obvious and common-sensical to the sentencer. This intuitive understanding may be difficult for the sentencer to articulate simply because normally $\mathrm{s} /$ he is not expected to provide it ${ }^{81}$ However, we should not assume that because sentencers tell us that sentencing does not rely on linear, deductive logic (that it is 'intuitive', 'comes from experience'; 'a hunch', and so on) that it is unpatterned, arbitrary or impossible to understand. 
As we saw above, the revelation that the sentencing decision process may not begin with consideration of the legal conviction neatly followed by consideration of 'aggravating and mitigating factors' seems to be greeted with some disappointment. However, such disappointment may not be confined to the study of sentencing, but to legal decision-making more generally. For example, in their study of problem-solving in civil law cases, Crombag et al. attempted to elicit accounts from experienced legal problemsolvers. ${ }^{82}$ They concluded that:

\begin{abstract}
While skilled problem-solvers may not be able to tell us explicitly how they proceeded while solving a problem, they are able to complete the solving itself. ... The most striking result was that what was said while thinking aloud created a rather chaotic unsystematic impression. Often a person seemed to have a solution, although a provisional one, at an early stage, for which he subsequently tried to find supporting arguments.
\end{abstract}

Crombag et al. argue that skilled legal problem solvers are like other skilled problem-solvers in that they tend to have a provisional solution in place early and to work backwards. Curiously, however, they describe these results as 'disappointing' ${ }^{83} \mathrm{Had}$ they, perhaps, hoped that their experienced legal problem-solvers might demonstrate a process of reasoning on the basis of legal analysis characterised by the supposed virtues of linear, deductive thought derived from first principles?

While it may be true that skilled problem-solvers (like lawyers) come to an early provisional solution and then try to find supporting arguments, can this finding be extended to judges? I would suggest that the nature of the sentencing decision process may not be very qualitatively distinct from the nature of the discretionary legal decision process more generally. ${ }^{84}$ The background of most judges in most adversarial law jurisdictions is one which results from years of experience as a successful advocate/solicitor. The nature of the adversarial process (as opposed to the inquisitorial one) is to represent one's client and achieve a favourable result rather than to find the 'truth' in any objective sense. ${ }^{85}$ The craft of lawyering demands working towards a final goal and locating and interpreting previous decisions which will promote that goal. In this regard, the character of the sentencing decision process may be little different from that performed by other makers of discretionary legal decisions. It may be reasonable to suppose that after so many years experience of lawyering this purposive approach may continue to be useful (albeit semi-consciously) to the lawyer who has been promoted (often part-time) to the bench. After all, few, if any, common law jurisdictions encourage or require judges to begin the sentencing process from any grounded process. Rather, judges are encouraged to base their decisions largely on experience. As Ashworth et al. observe from their interviews with judges about sentencing: 'Most judges described it as an instinctive process, using such terms as "instinct", "experience", "hunch" and "feeling". ${ }^{96}$ Thus, the giving of reasons for sentence may well be more to do with a publicly defensible and legally legitimate reconstruction of the process than revealing the full flow of consciousness in the decision process. ${ }^{87}$ 
In a comparative review of sentencing research, Albrecht states that ' $[t]$ he core problem in research on sentencing is still embedded in the question of which variables determine decision making within the criminal courts and which criteria actually account for variation in sentencing decision outcomes. ${ }^{88}$ There appears to be an assumption that sentencing can best (or only) be explained by abstracting individual 'pieces' of information from their case-context and analysing them as if they possessed some independent, discrete power. I would suggest that some traditional representations of the sentencing decision process employed by some systems of numerical guidelines, artificial intelligence, and some studies of disparity fail to capture the essentially holistic nature of the decision process preferring instead to assume that the decision process is so highly complicated that it can only be understood through expert linear, legal, and mathematical analytical models.

The result is that decision-makers (in this case judges) tend to feel alienated by the analytical complexity of the model and yet, despite its complexity, feel that the model is missing something essential. That essential, but missing quality lies in the dynamic but fluid interaction of the abstracted 'factors'. Analytical models fail to capture the importance of 'the whole case' about which judges so often speak. Information which analytical models extract from a case only has meaning to the purposive decision-maker in relation to the whole offence story. Rather than artificially analysing case information, a typology could be developed to reflect kinds of offence stories from the perspective of sentencing rather than legal conviction. A case story would not be analysed as a collection or combination of fragmented 'factors', but a reintegrated whole.

Thus far, discussion in this article has focused on the idea of approaching an understanding of the sentencing decision process in terms of typical offence stories. I will now turn to the place of offender information and its relationship with the idea of 'typical whole offence stories'.

\section{5. 'Offence' and 'offender' characteristics}

Both academic writing and sentencing reforms have tended to assume that sentencing either begins, or, should begin, with consideration of the offence, then orientate a sentence which is then adjusted in the light of the nature of the offender. For example, in his discussion of sentencing in Victoria, Fox documents the failure of attempts to establish a 'two-stage' sentencing procedure whereby sentencers first consider the offence and then the offender ${ }^{89} \mathrm{He}$ seems to lament the refusal of the Victoria Full Supreme Court to sanction such a two-stage procedure. That Court noted that the High Court expressly rejected the suggestion that a two-stage approach, opting instead, ' . . f for a global sanction taking into account the circumstances of the offending in their entirety. ${ }^{90}$ In their text on sentencing practice in Northern Ireland, Boyle and Allen also assume that the decision process begins with a general orientation towards punishment for the offence followed by consideration of individual offender characteristics: 
... the sentencer, having chosen the sentence range appropriate to the offence will next consider whether the sentence appropriate to the gravity of the offence should be reduce to reflect the presence of mitigating factors ... found to exist in the character and past history of the offender . . .91

Writing about sentencing in the then West Germany, Weigend remarks that:

Legal scholars argue that consideration of the appropriate sentence should consist of at least two stages: first, setting the sentence that reflects the offender's culpability; second, correcting it for his rehabilitative needs; and possibly further adjusting it to satisfy the demands of general deterrence. It is not likely that [sentencing] panels actually undertake these complicated mental operations.92

\section{(a) Reform and 'the offence' and 'the offender'}

The judged seriousness of a 'typical whole offence story' is itself informed and determined by the nature of the offender and his/her relationship with the victim, and likewise the offender's nature is informed and determined by the offence story. In his research into the flow of criminal cases and the nature of court organisational culture, Feeley observes that, ' . . . for a charge to assume meaning it must be given substantive content by a description of the incident and information about the defendant's character, habits and motivation. ${ }^{93}$ Sentencers must necessarily make judgements about the moral responsibility of 'the offender' if they are to understand and interpret the seriousness of 'the offence' before them. Indeed, section 29 of the 1991 Criminal Justice Act of England and Wales may arguably have been so unpopular with sentencers ${ }^{94}$ at least in part, because it tried, (or, at least as it appeared to judges and others), to structure sentencing, according to an artificial distinction between offence and offender 'factors'.

This may also partly explain the judicial resistance which the United States federal sentencing guidelines have encountered. The system of guidelines is operated by a grid which attempts to divorce 'offence' and 'offender' information from each other. The attempt by the federal guidelines to abstract issues concerning the 'offence' and those concerning 'the offender' from the whole case is not one that judges feel comfortable with, because '[b]efore the guidelines, judges often considered offender characteristics reflecting blameworthiness ... '99 However, it seems probable that judges still do consider what are labelled 'offender' characteristics in order to determine blameworthiness (what is labelled the 'offence') despite the instructions of the guidelines. Perhaps it is the attempt to force sentencers to implement a practical (rather than a notional) divorce between the so-called 'offence' and 'offender' characteristics from each other that has led to the deep unpopularity of the United States federal guidelines and their widespread 'circumvention' ${ }^{96}$

Tonry rightly criticizes the 'two-dimensionality' sentencing guideline grids which are based on a two axis grid 'machine':

Reduced to their core elements all, all sentencing guidelines grids are fundamentally the same: two dimensional tables that classify crimes by their severity along one axis and criminal records by their extent along another . . . Judges and prosecutors and other 
officials make decisions about whole people, and not about generic offenders who have committed $X$ and have a criminal history $Y$... Judges and lawyers ... resist the refection of individuals into crime and criminal history amalgams.97

Tonry's criticism of the mathematical, algebraic formula of $\mathrm{X}$ offence score plus $Y$ offence score determining the sentence is a valid one. 'Offence' and 'offender' information do not work discretely in the sentencing decision process: the interpretation of one is integral to the other. For example, the 'situation' of the offender and his/her relationship with the victim, the offender's criminal, medical, social, psychological history all inevitably confer meaning on the offence story and on questions of harm and culpability.

However, Tonry's assertion that judges (especially trial judges) are reluctant to treat ' . . people as stereotypes rather than individuals' seems a little surprising. ${ }^{98}$ As was argued above, the criminal process produces normalized, and typified cases. There may be a variety of types of cases which appear before sentencers and which are (re)constructed by sentencing process itself, but they are not infinitely unique in the way that individual persons are infinitely unique as Tonry appears to imply. In thinking about the relationship between 'the offence' and 'the offender', information needs to be re-thought in terms of types of whole case stories rather than in terms of unique individuals. Sentencers do not make decisions about completely unique whole individual persons, but as examples of types of whole case stories.

(b) Philosophical theories of punishment and 'the offence and the offender'

What might this mean for normative theories of punishment such as 'desert'? A9 Although essentially 'offence'-based, attempts to implement 'desert' have had to allow the inclusion of what the theory labels as 'offender' characteristics where 'relevant' to the offence. The practical difficulty in implementing 'desert' theory has been in where the line should be drawn between the relevance and non-relevance of so-called offender information to the issues of harm and culpability (which desert regards as primarily properties of 'the offence'). Arguably, this illustrates the difficulty in making and implementing a practical distinction between the 'offence' and the 'offender' when the decision of the sentencer requires one single overall outcome in response to the judged seriousness of the whole story of the case. The sentencer cannot in practice make a discrete decision about the 'offence' and then a discrete decision about the 'offender', but rather must reach one decision outcome.

Tonry holds the implementation of desert in part responsible for the failure of the United States federal guidelines. ${ }^{100} \mathrm{He}$ criticizes desert for ignoring the differences between offenders, but to do so is to criticize the quintessence of desert. ${ }^{101}$ The problem for desert is that it attempts to abstract issues of harm and culpability from the whole case story, and that necessarily incorporates a judgement about the offender's situation and character. 
Parallel problems may be identified in other philosophical justifications for how and why punishment is practised. For example, rehabilitative and treatment models inevitably necessitate a relative judgement about the moral responsibility and 'appropriateness' of the offender's behaviour in order to interpret the seriousness of the whole case. Therefore, I would suggest that as an interpretative category for research into the sentencing decision process, philosophical justifications of punishment fail to illuminate the practice of that process. Rather, the role of philosophical justifications of punishment may lie more specifically in their ability to provide symbolically defensible normative accounts of how or why societies punish. ${ }^{102}$ This is not to deny the importance of philosophical accounts, but rather to suggest that their explanatory value may lie at the heart of cultural questions. ${ }^{103}$

\section{6. 'Typical whole case stories'}

I have argued for a re-appraisal of traditional approaches to conceptualizing and representing and advocated consideration of an alternative approach based on typical whole case stories. How might such an alternative re-presentation of cases look? The key feature would be the radical reintegration of 'offence and offender' and the abandonment of supposedly universal, independent 'aggravating and mitigating factors': information abstracted from their case context with supposedly discrete and universal power over the decision outcome. Since 'aggravating and mitigating factors' are only meaningful in the context of their case story; types of whole case stories could be represented. Such a taxonomy would reintegrate offence and offender features. One hypothetical example might look as follows :

This is a case about a young man who has recently broken up with his girlfriend (and now has limited contact with his one-year-old daughter). He has since become increasingly drug-dependent and committed robbery using a knife against a chemist. Until being remanded in custody, he had, over a relatively short period of time, been robbing a relatively small quantity of class 7 drug (known locally as ' $O$ ') from chemists in areas A, B of the city. He would then sell some of it on to similar-aged acquaintances and consume the rest himself.

This may arguably be a fairly typical kind of case story upon which sentencers decide in Scotland. This is not to say that many individuals are exactly as described, but rather that patterns of typified whole case stories emerge from the criminal process. The patterns may differ through time and space. However, the stories which need to be developed would involve the natural, holistic narration of what is called 'offence' and 'offender' information. 'Knowing' that the offender is 'drug-dependent', that it was ' $O$ ', that he sold it on to acquaintances rather than younger people at 'raves', that he kept some for himself tells the sentencer something about the motivation and of the offender's behaviour. Armed with this 'knowledge', the sentencer is able to interpret both the character and behaviour of the offender because the one 'explains' the other. This is distinct from an attempt to abstract 
individual pieces of 'information' from their whole case context and imply that they have some independent influence on the decision process.

As judges continually emphasize, each case is unique at least in some sense. So while the 'plot' of different kinds of case stories may closely follow typical patterns, the precise detail concerning each case means that each case may vary slightly from the basic, normal story ${ }^{104}$ (and just different enough to fulfil the judicial rhetoric that "justice dictates each case must be judged on its own merits'). However, the effective disposal of 'streams of cases'105 depends on the ability of the criminal process to communicate expectations and cues which guide judges in answering the question 'what type of case is this?'

It may be that by attempting to develop and implement a research typology based on judicial images of typical whole case stories, the question of 'disparity' needs to be re-examined. Yet to what extent could we expect judges to share similar images of typical whole case stories? After all, judges frequently work in isolation and share little systematic information about sentencing. ${ }^{106}$ On that basis it might be expected that individual sentencers would vary markedly in line with their individual conceptions of typical whole case stories. Indeed, it seems possible to identify one tradition within sentencing research, particularly popular in North America, which posits that an individual judge's 'philosophy' of punishment and how this fits into his/her individual ideological socio-political world-view is one (or even the) main determinant of sentencing decisions. ${ }^{107}$ However, if it is true that whole case stories are largely constructed and typified by the criminal process before they even reach the judge, then it is also true that the agenda for judicial sentencing is in practice largely circumscribed by the construction, cues, and expectations of earlier and later points in the criminal process. This is not to suggest that judicial sentencing is completely reactive or passive, but rather to emphasize that sociolegal research has shown that official, formal discretion is regulated and patterned by social rules. ${ }^{108}$ Indeed, this might explain why we may discover a surprisingly high degree of broad agreement in the development of a research tool based on typical whole case stories. ${ }^{109}$

In the introduction to this paper I noted that some writers have observed the limited ability of research to explain sentencing behaviour. ${ }^{110}$ As Gottfredson has remarked, 'it would be difficult to find other decision problems affecting critically the liberty and futures and lives of large numbers of people in which decisions are made with so little knowledge of the way in which they are made.'1' No doubt this has been obstructed by judicial sensitivity to researchers gaining and maintaining access to research. ${ }^{112}$ However, there may be some conventional assumptions made by research which themselves cause sentencers discomfort. These centre around a legalanalytical paradigm of decision-making which may ask sentencers to outline their 'philosophy' of punishment and how this determines their practices, or what 'aggravating and mitigating factors', they consider most important and 
why, or, what weight that give to 'offence' as opposed to 'offender factors' and so on. While judicial accounts in court are often couched in terms of analytical 'legal and philosophical principles', I have attempted to argue that the sentencing decision is in fact a far more intuitive and socially constructed practice than legal rhetoric implies.

\section{CONCLUSION}

The attempts to 'describe' and 'explain' the sentencing decision process necessarily implies the same questions concerning the comparison of similar cases. I have argued that the conception and representation of similarity has been dominated by legalistic starting points which may in fact be of little help in representing similarity meaningfully from the perspective of the sentencing decision as a process. The question of the similarity of cases with more than one conviction has received perhaps less attention than it might. A legal-analytical approach in which a 'most serious' offence is moderated by further 'factors' is artificial.

An alternative approach is informed by research in discretionary decisionmaking in other parts of the criminal process to try to develop an understanding and representation of 'typical whole case stories'. I have suggested that the decision process of judges may not be very different in character to that of other discretionary decision-makers and that such research should not be discounted in thinking about judicial discretion. Indeed, judges' professional background may lead us to suppose that they approach the decision process purposefully and pragmatically rather than in a formal, linear fashion. The public giving of reasons as justification for decisions (often clothed in the analytical language of philosophical justifications of punishment) should not be taken as a full, comprehensive or transparent account of the decision process. Further, the search for 'aggravating and mitigating factors' and dichotomous representation of cases in 'offence' and 'offender' information suggests an artificially deductive and analytical account of the decision process.

This article has attempted to suggest an alternative way in which we might better understand and represent the sentencing decision process. However, it has not attempted to normatively evaluate different philosophical justifications of punishment (that is, for what 'reason', if at all, we ought to punish). ${ }^{113}$ I have tried to suggest that these questions have not and cannot empirically explain the decision process in practice. Rather, philosophical justifications provide a vital powerful symbolic function in the cultural debate about punishment.

However, at least two (no doubt more) theoretical questions seem to remain. The first relates to the possibility of adapting the typical whole case stories approach to areas beyond the sentencing decision. The second relates to accountability in sentencing (and discretion) through the symbol of legalphilosophical rhetoric. I will address each of these briefly. 


\section{Discretionary (legal)? decision making}

This article has argued that the implications of research into the exercise of discretion in other areas of the criminal process should be considered in thinking about how we understand and research the sentencing decision process. Equally, the use of typical whole case stories may have implications for other areas of discretionary legal decision making and the use of discretion in non-legal settings. Is there anything distinctive about the decision process outwith primarily legal institutions? How closely does the character of the sentencing decision process closely relate to other areas of discretionary decision-making - for example, the process of grading a student assignment? If the character of the decision process between discretionary decision-making in this area and that of sentencing is not qualitatively distinct should we be talking of discretionary 'legal' decision-making at all? Would it be more useful to think simply of discretionary decision-making?

\section{Public accountability and symbolic justification}

Perhaps the attempt to construct legal-analytical models of the decision process may in part be influenced by symbolic public declarations of the courts themselves. The giving of publicly declared reasons for a decision tend to be couched in legal analytical terms. Has this more to do with the necessity to fulfil a popularly-held expectation of the 'principles' of justice than a revelation of the stream of consciousness in the decision process? 'If [official] reasons [for decisions] have a place in court, it is because they are defensible, not because they are true.'114 It may be that the official nature of sentencing reform through official sentencing commissions and councils could itself lead to a reluctance to depart from officially-sanctioned and accepted 'explanatory' categories of the sentencing process (for example, 'desert', 'aggravating and mitigating factors', 'offender characteristics', and so on). To depart from these categories in a public way may invite accusations that sentencing is officially recognized to lack the symbolically 'lawlike' features of linear, deductive, analytical legal reasoning and thus be admitted to be without 'order'. An official body of reform, as found for example in sentencing commissions and councils, may feel bound to employ these rhetorical explanatory categories in order to support the symbolic idea of the juridical character of the decision process.

Thus, the official, public style of these reforms may provide legitimation and one kind of 'accountability', but in fact these accounts tell us little about the actual sentencing decision process itself and more about the demands of legal rhetoric. However, this is not say that legal rhetoric is unimportant or should be ignored, but merely that we should recognize that it has a symbolic role of legitimation rather than an instrumental role. It may be that the symbolic role tell us more about law as communication. As Wilkins has observed, '[p]erhaps our main problem is that we have not been honest 
in our language in discussing criminal justice procedures. We have tried to believe that our sanctions were rational when they were mainly symbolic. 115 For reform the dilemma is that to admit the symbolism (rather than instrumentalism) of sanctions may risk undermining the power of the idea of law.

\section{NOTES AND REFERENCES}

1 For example, K.C. Davis, Discretionary Justice: A Preliminary Inquiry (1969); Lord Taylor, 'Judges and Sentencing' 38(4) J. of the Law Society of Scotland 129-31

2 N. Lacey, 'The Jurisprudence of Discretion: Escaping the Legal Paradigm' in The Uses of Discretion, ed. K. Hawkins (1994) at 377.

3 J. Rumgay, 'Custodial Decision-Making in a Magistrates' Court' (1995) 35 Brit. J. of Criminology at 202.

4 Generally, I will refer to judicial sentencing as opposed to sentencing by other bodies such as prosecutors.

5 A. Ashworth, E. Genders, G. Mansfield, J. Peay, and E. Player, 'Sentencing in the Crown Court: Report of an Exploratory Study', University of Oxford Centre for Criminological Research, occasional paper no 10 (1984); Taylor, op. cit., n. I.

6 R. Hood, Sentencing in Magistrates ' Courts: a study in variation of policy (1962) at 16.

7 L.T. Wilkins, 'Perspectives on Court Decision-Making' in Decision-Making in the Criminal Justice System: Reviews and Essays, ed. D.M. Gottfredson (1975) at 69.

8 For example, Scottish Office, Criminal Proceedings in the Scottish Courts 1992 (1993); Home Office, Notifiable Offences (1996); Home Office, Cautions, Court Proceedings and Sentencing: England and Wales 1994 (1995).

9 The principle issue of similarity concerns the judged 'seriousness' of cases.

10 K.W. Patchett and J.D. Mclean, 'Decision-making in juvenile cases' (1962) Criminal Law Rev. 699-710.

11 E. Green, Judicial Attitudes in Sentencing: A study of the Factors underlying the Sentencing Practice of the Criminal Court of Philadelphia (1961).

12 Hood, op. cit., n. 6.

13 R. Tarling, Sentencing Practice in Magistrates' Courts (1979).

14 id., at p. 14.

15 id., at p. 27.

16 Ashworth, et al., op. cit., n. 5; C. Fitzmaurice and K. Pease, The Psychology of Judicial Sentencing (1986); Hood, op. cit., n. 6; R. Hood, in collaboration with G. Cordovil, Race and Sentencing : A Study in the Crown Court (1992).

17 L. Nicholson, The Deferred Sentence in Scotland (1992).

18 J. Shapland, Between Conviction and Sentence: the Process of Mitigation (1981).

19 N. Hutton, C. Tata, and J. Wilson, 'Sentencing and Information Technology: Incidental Reform?' (1995) 2 International J. of Law and Information Technology 255-86.

20 I am using the term 'conviction' to refer to official, legal taxonomy - sections of Acts of Parliament, headline common law terms.

21 One notable exception is in M. Walker, 'Criminal Justice and Offenders' in Interpreting Crime Statistics, ed. M. Walker (1995) at 28-9.

22 The term 'case' is used in variety of contexts with differing meanings. In the context of sentencing it refers to one person sentenced, even if for more than one conviction.

23 N. Hutton, A.A. Paterson, C. Tata, and J.N. Wilson, 'A Prototype Sentencing Information System for the High Court Justiciary: Report of the Study of Feasibility' (1996).

24 This tends to be the approach taken by systems of recording information which rely on an administrative source for their data. For example: 'Where more than one conviction receive 
the same (or a combined penalty), then the main charge is the one judged by the police (who provide the information) to be the most serious.' (Scottish Office, op. cit., n. 8).

H. Parker, M. Sumner, and G. Jarvis, Unmasking the Magistrates (1989); Hood, op. cit., n. 16; I. Potas, 'The Sentencing Information System of New South Wales: Promoting Consistency in Sentencing Through Computerisation' (paper presented to The Commonwealth Magistrates and Judges Association, Sydney, 1991); N. Hutton, and C. Tata, Patterns of Custodial Sentencing in the Sheriff Court (1995); C. Tata, J. Wilson, and N. Hutton, 'Representations of Knowledge and Discretionary Decision-Making by Decision Support Systems' (1996) $1 \mathrm{~J}$. of Information, Law and Technology, http://elj.warwick.ac.uk/elj/jilt/artifint/2tata/.

26 Potas, id; Scottish Office, op. cit., n. 8.

27 Hutton and Tata, op. cit., n. 25; Tata et al., op. cit., n. 25.

28 Hutton et al., op. cit., n. 23.

29 Hutton and Tata, op. cit., n. 25.

30 Some apparent support for this view can be found in A. Alschuler, "The Failure of Sentencing Guidelines: A Plea for Less Aggregation' (1991) 58 University of Chicago Law Rev. 901-51; D. Parton, M. Hansel, and J.R. Stratton, 'Measuring crime seriousness: lessons from the national survey of crime severity' (1991) 31 Brit. J. of Criminology 72-85.

31 Ashworth et al., op. cit., n. 5.

32 Hutton et al., op. cit., n. 19.

33 In this context, the term 'offences' is intended to be distinguished from 'convictions' which refers to the strict criminal law charge of which a person was convicted. I refer to 'offences' in a broader way to include information which is meaningful to the sentencer concerning the incident(s) surrounding the commission of the conviction (this is perhaps akin to what lawyers call 'the facts' of a case as meaningful to the sentencer).

34 For example, T. Weigend, 'Sentencing in West Germany' (1983) Maryland Law Rev. at 63 , observes that: 'German courts ... treat sentencing as a subsidiary to the overriding concern in the information-gathering phase of adjudication: the determination of guilt or innocence.'

35 J. Shapland, 'Who Controls Sentencing? Influences on the Sentencer' in The Psychology of Sentencing: Approaches to Consistency and Disparity, eds. D.C. Pennington and S. Lloyd-Bostock (1987).

36 id., p. 78.

37 See, for example, D. McBarnett, Conviction Law, the State and the Construction of Justice (1981).

38 J. Baldwin, Pre-Trial Justice: a Study of Case Settlement in Magistrates' Courts (1985).

39 W. Waegel, 'Case Routinization in Investigative Police Work' (1981) 28 Social Problems $263-75$, at 265 . Original emphasis retained.

40 On the idea of 'normal crimes', see D. Sudnow, 'Normal Crimes: sociological features of the penal code in a public defender office' (1964) 12 Social Problems 255-76.

41 S.R. Moody, and J. Tombs, Prasecution in the Public Interest (1982).

42 id., p. 45.

43 id., pp. 53-4.

44 P. Duff, 'Diversion From Prosecution Into Psychiatric Care: Who Controls the Gates?' (1997) 37 Brit. J. of Criminology 15-35.

45 Sudnow, op. cit., n. 40.

46 id., p. 260.

47 id., pp. 261-2.

48 J. Curran, and G. Chambers, Social Enquiry Reports in Scotland (1982).

49 S. Brown, Magistrates at Work: Sentencing and Social Structure (1991) at 9.

50 H. Giller and A. Morris, "What Type of Case is This?" Social Workers' Decisions about Children Who Offend' in Discretion and Welfare, eds. M. Adler and S. Asquith (1981).

51 id., at pp. 79-80.

52 A.S. Elstein, L.S. Shulman, and S.A. Sprafka, Medical Problem Solving (1978). 
53 R.M. Emerson, 'Holistic Effects in Social Control Decision-Making' in The Law and Society Reader, ed. R. Abel (1995) 161-84.

54 Shapland, op. cit., n. 18.

55 Ashworth et al., op. cit., n. 5.

56 M. Feeley, The Process is the Punishment: Handling Cases in a Lower Criminal Court (1979) 167-77.

57 Shapland, op. cit., n. 35; R. Ericson, Making Crime: A study of Detective Work (1981); R. Ericson, Reproducing Order: A study of Police Patrol Work (1982).

58 In this sense we might usefully think about the site of the sentencing decision process beyond that of the decision-making institution (the sentencing judge), but located through the criminal process.

59 L. Nicholson, The Deferred Sentence in Scotland (1992).

60 id., at p. 14.

61 B. Barnes, Interests and the Growth of Knowledge (1977).

62 P. van Duyne, 'Simple Decision Making' in Pennington and Lloyd-Bostock, op. cit., n. 35 , at p. 147

63 id. An 'open problem' is characterized by van Duyne as one where the problem-solver cannot objectively and irrefutably determine whether his or her solution is the correct one.

64 Tata et al., op. cit., n. 25.

65 Hutton et al., op. cit., n. 19.

66 Ashworth et al., op. cit., n. 5.

67 For example, see G. Nicholson, Sentencing: Law and Practice in Scotland (2nd ed., 1992); N. Walker and N. Padfield, Sentencing: Theory, Law and Practice (2nd ed., 1996); C.K. Boyle and M.J. Allen, Sentencing in Northern Ireland (1990); M. Findlay, S. Odgers, and S. Yeo, Australian Criminal Justice (1994), see 213-46.

68 For example, see: F. Kort, 'Content Analysis of Judicial Opinions and Rules of Law' in Judicial Decision-Making, ed. G. Schubert (1963); J. Hogarth, Sentencing as a Human Process (1971); Hood, op. cit., n. 16; Hutton and Tata, op. cit., n. 25; A. Lovegrove, Judicial Decision Making, Sentencing Policy and Numerical Guidance (1989); D. Moxon, Sentencing Practice in the Crown Court (1988).

69 There is a tradition of sentencing research which attempts to model the sentencing decision process as if the sentence decision were akin (or at ought to be akin) to deducing the sentence from algebraic modelling ('If $\mathrm{X}$ factor plus $\mathrm{Y}$ factor minus $\mathrm{B}$ factor then $\mathrm{Z}$ decision') models. This is often seen as the building block for the production of systems of aritificial intelligence.

70 Perhaps this is similar to what Alschuler has in mind when he writes in his conclusion to his article criticizing the United States sentencing guidelines of the 1970s and 1980s: 'By focusing on paradigmatic crimes rather than abstract crime categories, a Sentencing Commission could escape this apparent bind [of artificial aggregation]' (Alschuler, op. cit., n. 28, at p. 949). However, he does not elucidate this suggestion any further.

71 Shapland, op. cit., n. 18

72 id., at p. 85.

73 M. Tonry, Sentencing Matters (1996), at 23.

74 See, for example, Alschuler, op. cit., n. 30.

75 See, for example, A. Kapardis, 'Sentencing by English magistrates as a human process' in Pennington, and Lloyd-Bostock, op. cit., n. 35; Lovegrove, op. cit., n. 68

76 Weigend, 1983, op. cit., n. 34 , at p. 81 .

77 id, at p. 81.

78 R. Fox, 'The Meaning of Proportionality in Sentencing' (1994) 19 Melbourne University Law Rev. 489-511, at 510.

79 id., at p. 510.

80 See, also, M. Miller, 'Guidelines Are Not Enough: The Need for Written Sentencing Opinions' (1989) 7 Behavioral Science and the Law (Sentencing). 
81 In a similar vein, Feeley observes that, "[a]lthough prosecutors and defense attorneys tend to become inarticulate when presses to specify exactly how to they evaluate the "worth" of a case, they claim to know it intuitively.' Feeley, op. cit., n. 56, at p. 159.

82 H.F.M. Crombag, J.L. De Wijkerslooth, and E.H. van Tuyl van Serooskerken, 'On Solving Problems' (1975) $27 \mathrm{~J}$. of Legal Education 168-202.

83 id., at p. 169

84 N. Hutton, 'Sentencing, Rationality, and Computer Technology' (1995) $22 \mathrm{~J}$. of Law and Society $549-70$, argues that, (in Weberian terms), sentencing has remained a substantive irrational process, in contrast to the characteristic shift of modern western legal systems. However, while the sentencing process may be revealed as substantive irrational, I would suggest that it is a character which may be shared in common with, rather than in contrast to (as Hutton suggests), other areas of discretionary (legal) decision making

85 For wider discussion on this point, see M. McConville, A. Snaders, and R. Leng, The Case for the Prosecution (1991).

86 Ashworth et al., op cit., n. 5.

87 I have tried to suggest here that one possible reason for the purposive and pragmatic character of sentencing may originate from the experience of problem-solving as lawyers in a context of adversarial and civil criminal process. This does not tackle the character of such decision-making in inquisitorial or other non-adversarial schemes. It may be, on the other hand, that since lawyering is rather less adversarial in practice than is often supposed (see McConville et al., n. 85) that this formal context makes little difference in practice.

88 H. Albrecht, 'Sentencing Disparity - a comparative study' (1994) 2 European J. of Criminal Policy and Research, at 99. Emphasis added.

89 Fox, op. cit., n. 78.

90 id., at pp. 507-8,

91 C.K. Boyle and M.J. Allen, Sentencing in Northern Ireland (1990), at 240.

92 Weigend, op. cit., n. 34 , at p. 65.

93 Feeley, op. cit., n. 56, at pp. 160-1.

94 See, for example, I. Brownlee, 'Taking the strait-jacket off: persistence and distribution of punishment in England and Wales' (1994) 14 Legal Studies 295-312.

95 M. Miller, 'Rehabilitating the federal guidelines' (1995) 78(4) Judicature: the $J$. of the American Judicature Society, at 183.

96 id.; Tonry, op. cit., n. 73; R.S. Frase, 'State sentencing guidelines: still going strong' in Tonry, id.

97 Tonry, id., at pp. 15-19.

98 id., at p. 19.

99 For a fuller exposition of 'desert', see, for example, A. von Hirsch, Doing Justice: The Choice of Punishments (1976); A. Von Hirsch, Past or Future Crimes (1985).

100 Tonry, op. cit., n. 73.

101 It might be argued that one of the virtues of desert theory is that it advocates the prohibition of attempts to make judgements about the character of an offender and attempts to prevent offenders from being punished again for past offending. However, as I attempt to show, it is not possible to make practical distinctions between the nature of the 'offence' and the nature of the 'offender'.

102 For discussion of a sociological understanding of the role of philosophical justifications of punishment see, for example, D. Garland, Punishment and Modern Society (1990).

103 Of course the cultural question concerning how societies attempt to justify the 'need' to punish and the empirical question of how the sentencing decision is processed are interrelated not least at the point where judges attempt to justify their decisions publicly. However, as I argue later, this should not lead us to assume that the reasons given in court are the obvious category for explanation of 'why' the judge passed the sentence s/he did. 
104 One intriguing question is "how does a sentencing process based on typification and normalization cope with slightly different cases and how do new "typical whole case stories" appear"? It may be that one way of trying to understand this is through the interaction between typical whole stories. In other words, a variation of information on a typical whole story theme brings with it meanings from another typical whole story with which it is associated. Their interaction may bring about a new (or at least 'different') kind of typical whole case story.

105 Emerson, op. cit., n. 53.

106 Hutton and Tata, op. cit., n. 25.

107 One of the most sophisticated examples of work in this 'tradition' is that by Hogarth, op. cit., n. 68.

108 See for example, M.P. Baumgartner, 'The Myth of Discretion' in The Uses of Discretion, ed. K. Hawkins (1992); Waegel, op. cit., n. 39, argues at p. 264 that conventional research strategies focusing on decision-making variations between individuals and between functionally similar organizations have severe limitations. A more fruitful approach for studying processing outcomes takes as its focus the shared categorization schemes used by members in organizing their day-to-day activities.

109 On this point see, for example, Hutton et al., op. cit., n. 23; M. Cavadino and P. Wiles, 'Seriousness of Offences: The Perception of Practitioners'(1994) Criminal Law Rev. 489-98; C. Tata and N. Hutton, 'What "Rules" in Sentencing? The Custodial Sentencing Patterns of Sentencers Working in a Small Jurisdiction in the Absence of Rules' (1997, forthcoming) Brit. J. of Criminology. While none of these studies go as far as to develop 'typical whole case stories' they do avoid some of the difficulties presented by a more legal-analytical approach. These studies found a surprising degree of broad agreement in the assessment of seriousness once the practical process of research, using hypothetical materials, gets underway. It may be that attempting to develop a scheme with judges in the absence of case material produces generalized and unspecific remarks about the need to treat each case on its merits (Hutton et al., id.).

110 Shapland, op. cit., n. 35; Lacey, op. cit., n. 2.

111 D.M. Gottfredson, 'Diagnosis, Classification and Prediction' in Gottfredson, op. cit., n. 7.

112 See, for example, the experience documented by Ashworth et al., op. cit., n. 5 .

113 This may include what North American writers have labelled 'unwarranted disparity'. At least in the United States of America, the most discussed kind of disparity relates to racial disparity. However, how far this is directly attributable to judicial sentencing is debatable and may, in part, depend on the degree of discretion which judges have in practice. For example, Free concludes that racial disparities in sentencing are largely attributable to rates of arrest and the pre-judicial sentencing stages rather than at the judicial sentencing stage (M. Free, African Americans and the Criminal Justice System (1996)).

114 Fitzmaurice and Pease, op. cit., n. 16, at p. 45.

115 Wilkins, op. cit., n. 7, at p. 81. 